\title{
Legal Regulation of the Use of Artificial Intelligence: Problems and Development Prospects
}

\author{
By Olena Yara ${ }^{1}$, Anatoliy Brazheyev ${ }^{2}$, Liudmyla Golovko ${ }^{3}$, Viktoriia Bashkatova ${ }^{4}$
}

\begin{abstract}
The article considers the advantages and disadvantages of using artificial intelligence (AI) in various areas of human activity. Particular attention was paid to the use of AI in the legal field. Prospects for the use of $\mathrm{AI}$ in the legal field were identified. The relevance of research on the legal regulation of the use of AI was proved. The use of AI raises an important problem of the compliance with general principles of ensuring human rights. Emphasis is placed on the need to develop and use a Code of ethics for artificial intelligence and legislation that would prevent its misapplication and minimize possible harmful consequences.
\end{abstract}

Keywords: artificial intelligence, legal regulation of the use of artificial intelligence, protection of human rights, Code of ethics for artificial intelligence, the right to a fair trial

\section{Prospects of the Use of AI in the Legal Field}

Although in today's world there are more and more debates about AI and the feasibility of its use, the development of computer technology has had a significant impact on all spheres of human life and the increasing use of AI is inevitable. This also applies to the legal sphere.

Mobile applications for lawyers, analytical online platforms, online contract builders, smart offices of law firms - all of this is already actively functioning in the legal field. Currently, an innovative economy and information society, when the order and analysis of documents are performed automatically thanks to robotization and digital technologies (for example, drafting contracts, claims, etc.), the cost of legal services is decreasing. This is beneficial to clients and gives rise to competition among lawyers for primacy, and improves the quality of services. AI helps people in conducting special examinations, and the convenience of the interfaces of the proposed products (for example, in combination with business simulation, etc.) and their round-the-clock support will attract customers due to the creation of additional opportunities for them. Instead, lawyers will have the opportunity not to be "tied" to offices and independently determine their work schedule (Kravchuk, 2019).

Increasingly, AI is used in government agencies. For example, the Ministry of Justice of Ukraine is starting to use software "Cassandra" with elements of AI, which gives the opportunity to analyze the possibility of repeated violations of the law by a criminal.

| $1 \mathrm{PhD}$., Dean of the Faculty of Law of the National University of Life and Environmental Sciences of Ukraine ${ }^{2}$ Head of the NGO "Back to Life"

${ }^{3} \mathrm{PhD}$., associate professor of the Department of International Law and Comparative Law of the National 
Punishment for the crime is set by the court, but in order to help it in this, there is a document called "Pre-trial report", which is prepared by probation officers, which is the part of the Ministry of Justice of Ukraine. This document describes the identity of the accused, as well as an assessment of the likelihood of him/her committing new crimes. Accordingly, software "Cassandra" automates this process. The probation officer, having put answers to questions within the software, receives an estimate of the probability of committing a new crime from 0 to 97 . This assessment is carried out by an algorithm that gives points for a particular question, and then summarizes them (The Ministry of Justice of Ukraine, 2020).

Here is another example of the use of AI in determining the possible recurrence of a crime. Now in some states of the USA (in particular in the states of New York, California, Florida, Wisconsin) a program called COMPAS is used. The software was created by the privatelyowned company Northpointe (now Equivant) in 1998 and has evolved over the years with increasing data in the field of criminology and correctional practices. The software uses algorithms in three main ways - to assess the risk of general recidivism, violent recidivism, or the possibility of escape (Young, 2018).

The most obvious drawback of using aforementioned programs is that the decisions are based only on known data. If the offender has not been previously convicted, his "profile" will be clean, so the program will consider him less of a risk. Although a combination of other factors may lead prosecutors and judges to different considerations. There are cases where the suspect / accused was involved, but for some reason they fell apart (insufficient evidence base, procedural violations, etc.). Due to the non-linearity and heterogeneity of other data, it is impossible to build efficient algorithms. Let's imagine there is a criminal who has been searched for several years and who has other crimes committed. But during these few years his life changed a lot - he became a religious person, started a family, took up charity work. Of course, this is not a guarantee, but the likelihood of escaping or reoffending can be greatly reduced. Another example is the formerly venerable and kind teacher, a father of many children and a conscientious taxpayer who took a slippery path and began the production of methamphetamine with all the criminal consequences of such activities. What will the machine say? There can be many additional conditions. The program has efficiency based on common patterns, excluding any items that do not match them (Cherniavska, 2020).

The use of AI also has a number of advantages. Overcoming human mistakes is one of them. A significant amount of cognitive biases is inherent in humans. Nobel laureate Daniel Kahneman, a behavioral economics researcher, in his book "Thinking Fast and Slow" described about 25 of the most common psychological mistakes people make when evaluating facts and making decisions (Kahneman, 2011). AI is devoid of these shortcomings of the human psyche, at least in theory, is able to provide a much more objective result of analyzing a complex set of facts and make a more rational decision. If we take into account that AI does not have emotions, cannot feel sympathy or antipathy for a person, does not require money, etc., then we will get an obviously more fair and independent judge (Zaiets, 2020).

Given the above advantages of using AI in the legal field, we should expect an increasing use of AI in providing legal advice. A promising area of research in this area can be during the provision of legal advice, the use of AI in identifying the emotional state of the client 
and thus creating opportunities in addition to the actual legal support, provide maximum psycho-emotional support to the client, analyze his/her mental state, identify possible depressive disorders, neuroses, psychosis, aggression, suicidal ideation and prevent offenses on this ground.

\section{Other Areas of Application of AI}

The scope of use of AI is very wide. In this section, we want to draw attention to the main trends.

Jonathan P. Rowe and James C. Lester in their studies point to the possibility of using AI for personalized preventive medical care for adolescents (Rowe, 2020). This is a promising area of research that can help improve adolescent health.

AI can be used in the system of psychological, medical, psychosocial counseling. In addition, AI can be used during the provision of services to children and adolescents, education, as well as during the provision of services for children with disabilities in order to support parents in fulfilling their parental responsibilities and protecting children.

There are already interactive assistants and adaptive learning programs in the world that use AI to personalize the educational process and simplify certain technical tasks. AI can perceive much more information than humans and therefore perform tasks much faster and more accurately. Some educational software developers have begun to use these benefits to create programs that would suit the needs of each student. For example, the non-profit organization Enlearn from Seattle has developed an adaptive educational platform in which machine learning can prescribe personalized curricula that would speed up the acquisition of knowledge for each student. The Enlearn team notes that their product breaks down the learning process into hundreds of small and inconspicuous components at once, to then analyze what exactly hinders student performance (Pierce, 2018). Then the program, like a real tutor, helps the student to tighten their weaknesses before continuing to learn new material.

For the systemic development of AI, the Ministry of Education and Science of Ukraine has created an expert committee, as well as developed the Concept for the Development of Artificial Intelligence, which is being submitted for public discussion today. The concept provides for: development of human capital and an emphasis on educating AI developers; the need to respect the right to confidentiality and privacy of a person; stimulating active use of AI technologies by public authorities and in the main industries of the country; development of entrepreneurship using AI (Concept of Artificial Intelligence Development, 2020). This is the first but necessary step, because Ukraine should apply the experience of the world's leading countries in adopting legislation aimed at the safe level of implementation and application of AI.

Despite its significant potential, the use of AI has its limitations. It works best when there is a huge amount of examples. However, in a risky area such as education, where the teacher cannot afford to make significant mistakes, it can be difficult to get many examples of how not to do so. AI should also use only the right data to draw the right conclusions. If inaccurate information suddenly reaches the total amount of data, the results will be false. In fact, there is no such thing as unbiased information. And some algorithms can make it even more subjective (How artificial intelligence can help education, 2020). 
Ukrainian police officers have repeatedly expressed interest in AI programs to help identify people prone to violence. Such programs would be very useful in combating domestic violence. And here there is a need for further research and development. According to psychologists, such programs would be useful for the prevention of violence in the family and against children, in particular, AI can be used during the work with the family, adolescents in accordance with the individual plan, in family group meetings, etc.

AI is already being used in aviation, manufacturing and vehicle management. The Traffic Organization Center of Ukraine plans to purchase a program for calculating and analyzing the behavior of cars, which will use AI. The system will provide information on how many cars are in a traffic jam and calculate the number of vehicles by direction of movement, depending on the time of day and other factors (Traffic in Ukraine, 2020).

Unmanned vehicles are another area of application of AI. Business car owners already use on-board computer features such as traffic tracking, adaptive cruise control, and a collision warning system that can release gas and stop the car on its own. At the same time, it should be noted that Hew Price and Jaan Tallinn, professors from University of Cambridge in 2012 published an article entitled "Artificial Intelligence - Can We Keep It in a Box?" and called for serious consideration of possible threats to the use of AI. According to scientists, cars using AI may simply be indifferent to humans, which will cause catastrophic consequences (Price, 2012).

Industrial robots, voice assistants, search systems also work with the use of AI. AI is able to determine individual health indicators from video analysis, in particular: pressure, pulse, breathing rate and stress level. Given these metrics, technology can detect patterns that indicate disease long before obvious symptoms appear. These capabilities allow to identify symptoms of the disease using video images from surveillance cameras. AI can also use information from the corresponding remote sensors. The combination of face recognition technology with sensors / infrared cameras for remote temperature measurement allows the creation of systems that autonomously identify people with fever in real time. Relevant systems are already being used to combat coronavirus, especially in China (Kulynych, 2020).

One of the newest directions is the use of AI to determine human emotions (emotion AI). It is an AI that enables a computer to recognize, interpret and respond to human emotions. A camera, microphone, or wearable sensor reads a person's state, and a neural network processes the data to determine an emotion. There are two main ways to analyze emotions: contact, with the usage of device that reads pulse, body electrical impulses and other physiological indicators. Such technologies can determine not only emotions, but also the level of stress or the likelihood of an epileptic seizure or committing suicide; contactless, when emotions are analyzed on the basis of video and audio recordings (the computer learns facial expressions, eye movements, voice and speech, gestures). Emotional AI can be used in marketing, in the development of game technologies, education, medicine and banking sphere. For example, in Russia AI was tested at Sberbank back in 2015, and three years later, Alfa-Bank launched its pilot for analyzing emotions from video. In addition to recordings from surveillance cameras, call recordings are also used. VTB launched a pilot project to implement emotional AI in 2019. And Rosbank, together with Neurodata Lab, have already tested the determination of customers' emotions by voice and speech. The client called the bank, and the neural network analyzed his state and the meaning of the 
conversation. In addition, the AI noticed pauses in the operator's speech, voice volume and communication time. This allowed not only to check the satisfaction with the service, but also to monitor the work of the contact center operators. Now Rosbank has implemented its own solution for emotion recognition. Instead of an acoustic signal, the system analyzes the text, while the accuracy remains high (Khrisanova, 2019).

Of course, these are not all areas where AI can be used. But from the information indicated above, we can see unlimited potential.

\section{Legal Regulation of the Use of AI}

In many countries around the world, the question arises about the need for legal regulation of AI. Gardner A.V.D.L. was one of the first who payed attention to this issue (Gardner, 1984).

There is also international scientific cooperation in the sphere of legal regulation of AI. The first international conference on the legal regulation of artificial intelligence was held in 1987. In 1991 International Association for Artificial Intelligence was established.

The UN is conducting a series of expert consultations to develop ethical guidelines for artificial intelligence. The Institute of Electrical and Electronics Engineers presented the document Ethically Aligned Design, which contains standards for the development and production of robots and AI (IEEE, 2016).

European Union is one of the leaders in the field of legal support for the use of AI. On 16 February 2017, the European Parliament adopted Resolution 2015/2133 (INL) on Civil Law Rules on robotics with recommendations for the European Commission. Although the resolution is not a binding act, it contains guidelines that the legislator will follow in the future when developing mandatory standards. The phrase "robotics and artificial intelligence" is used in the text of the Resolution, and this means that the authors of this document are not ready to separate these terms at this stage. It is proposed to consolidate the legal basis for the use of AI and the introduction of a pan-European system of registration of "smart" machines. According to the resolution, certain categories of robots should be assigned an individual registration number, which will be entered in a special register, where it is possible find detailed information about the robot, including information about the manufacturer, owner and terms of compensation in case of damage. It is proposed to introduce a compulsory insurance system for such technologies, under which manufacturers and owners of such technologies will be required to insure against potential damage from their use. Special attention in the Resolution is paid to the issue of personal data protection.

Most of the countries are not ready to legally recognize computer program as the author of the work of art and put AI on a par with human intelligence. For example, in 2012 an Federal Court of Australia ruled that a computer-generated work cannot be protected by copyright because it was not created by human (Federal Court of Australia, 2011).

AI is also not considered the author of the work in the United States and EU member states. In one of its judgments, the Court of Justice of the European Union even stated that copyright applies only to works which originality must reflect the author's own intellectual work (Judgment of the Court, 2009).

However, in Japan, lawmakers have proven to be much more progressive. Back in 2016, 
at a meeting of the State Commission on Intellectual Law, it was decided to begin developing regulations on copyright protection for products of creative activity created by AI. According to the agency's executives, such a step should be a support for companies working to create and implement innovations. The situation may change soon. And, as an example, the world community is already discussing the British startup Jukedeck, which has developed an AI capable of writing music, predicting that in 10-15 years the authorship of almost half of popular music will belong to AI (Kryvecky, 2017).

According to section 9 (3) of the United Kingdom Copyright Act, the author of a computer-generated literary, dramatic, musical or artistic work is "considered to be the person who made the preparations necessary to create the work" (Design and Patent Act, 1988). Thus, section 9 (3) of the United Kingdom Copyright Act protects works that do not have a human author, i.e. works that are not a direct result of human creativity.

Many researchers may agree with the approach to regulating the protection and ownership of machine-generated works, which is enshrined in UK law. However, a comprehensive analysis of the above-mentioned provisions of the UK Copyright Act in conjunction with the key principles of legal protection of copyright and the technical characteristics of AI systems makes it possible to identify problematic issues proposed by the UK legislator. First of all, it is not always easy and unambiguous to identify the "conditional" author of a work generated by an artificial intelligence system. Software developers, computer owners, and people who train and operate the computer can make the preparations that are necessary to create the work. A fairly natural question arises: which of them should be identified as the author? Despite sufficient progressiveness compared to many of its foreign counterparts, the current British copyright law speaks only of the protection of works that are, by and large, created by computer, and only if it is possible to identify the person who made the preparations necessary to create the work. However, it is not about potentially protective works generated by artificial intelligence systems autonomously, without any human intervention during content generation (Schwantner, 2018).

The new standards require AI researchers to describe the skills required to use an AI tool, the circumstances in which the AI is assessed, details of how humans interact with the AI, analysis of error cases, etc., granting by persons permission to use technology in them. That is, it turned out that it is impossible to leave the issues of using AI only at the mercy of developers and their clients. Legal regulation is required. For example, AI began to be used in medicine, offering various solutions for treating patients and performing the work, for example, of radiological imaging analysts. Some of the decisions were about drug research and AI decision making - as it turned out, they weren't always right. It was reported that the problem was that the choice of algorithms and the way they were applied were not regulated in any way by the standards of clinical trials (Vlasyuk, 2020).

Yuri Chubatyuk raises the issue of proper control of researchers and scientists working with AI. According to the researcher, the formation of a holistic culture of introduction of AI, areas of responsibility should be considered in advance.

Another very important point to consider now is that AI algorithms, which are currently at the center of the industrial revolution, will reflect and perpetuate the contexts and prejudices of those who create them. The difficulties faced by intelligent software in processing huge amounts of data are relatively harmless. Scientists promise to teach systems to solve such problems. But the learning process itself may depend on the racial, 
gender, political or other prejudices of the developers. Therefore, not only the implementation, but also the process of creating and developing innovations must be controlled by the relevant security authorities (Chubatyuk, 2020).

Another important issue of legal regulation of the development of AI concerns the expediency of banning (restricting) scientific developments in this area. Realizing the dangers of the uncontrolled development of AI, some scientists insist on banning relevant research and controlling the spread of technology as strict as in nuclear energy. However, as M.V. Karchevsky rightly points out, the ban on research in the field of AI cannot in principle become effective. In contrast to research in the field of nuclear weapons, the development of artificial intelligence is much cheaper and therefore more affordable. With the development of information technology, this activity will become even more accessible and dangerous. In such circumstances, the legislative ban on the development of AI will lead to a situation where the security and law enforcement agencies will be equipped much worse than criminals, terrorist organizations, etc. Despite the risk of dangers, an absolute ban on the development of artificial intelligence systems is impossible, legal regulation in this area should provide incentives for socially effective use of technology and minimize the risks of technology abuse (Karchevsky, 2017).

Judit Glavanits emphasizes the need to legalize technologies and products using artificial intelligence (Glavanits J, 2019). Libor Klimek stresses the need to introduce criminal liability for violating the law in the field of AI. (Klimek, 2019). Technology also raises concerns about the protection of personal data. Rastislav Funta and Gergely G. Karácsony draw attention to the need to protect personal data when using such technologies (Funta, 2019; Karácsony, 2019).

Thus, it can be concluded that the use of $\mathrm{AI}$ in various fields requires effective legal regulation that would protect people from abuse, as well as regulate the activities of AI developers. Without proper legal regulation, this industry cannot develop. With the development of technology, changes are needed in the legal regulation of AI so that the consequences of its use become useful for the whole society. Market forces with their own resources will not ensure successful development for the whole population. Legal regulation of $\mathrm{AI}$ is necessary in the following areas: privacy, data protection and data security issues, data processing, copyright for works created by AI, regulation of economic activities for the production of software and technologies with AI, development of the rules for using software, technologies or algorithms for working with human emotional states using machine learning and AI tools, which are necessary to prevent and minimize the risks of abuse of this technology, development of the Code of conduct for individual product using AI.

\section{Conclusions}

The use of artificial intelligence raises a wide range of legal, psychological, philosophical and ethical issues. Any development in the field of intelligent technology must work exclusively for the benefit of mankind. The use of AI even to determine a preventive measure as planned by the Ministry of Justice of Ukraine raises an important problem of the compliance of such decisions with general principles of ensuring human rights. When creating new programs using AI, it is necessary to simultaneously develop 
Code of Conduct for their use, which are necessary to prevent and minimize the risks of abuse of this technology and a Code of ethics that would be in line with the values of the European Union and the European Charter of Human Rights. Particular attention should be paid to legislation in the field of protection of personal data, information protection, intellectual property and competition.

\section{References}

Cherniavska, K. (2020). Artificial Intelligence at the Department of Justice. Retrieved from: https://ua.112.ua/statji/maliuska-khoche-vykorystovuvaty-shtuchnyi-intelekt-u-kryminalniiiustytsii-naskilky-tse-mozhlyvo-535538.html

Chubatyuk, Y. (2018). Artificial intelligence for Ukraine - risk or possibility. Retrieved from: https://www.everest.ua/analytics/shtuchnyj-intelekt-dlya-ukrayiny-ryzyk-chy-mozhlyvist/

Federal Court of Australia. Acohs Pty Ltd v Ucorp Pty Ltd [20212] FCAFC (2012). Retrieved from: https://jade.io/article/262011

Funta, R. (2019). Big Data as a challenge for data protection law and the protection of personality. Computer law, AI, data protection and the biggest technological trends. Proceedings of an international scientific conference. Danubius University, Sládkovicove, 7-16.

Gardner, A.V.D.L. An artificial intelligence approach to legal reasoning: Doctoral Dissertation. (1984). Stanford University, CA, USA, 214 p.

Glavanits, J. (2019). Blockchain technology in the glance of consumer protection. Computer law, AI, data protection and the biggest technological trends. Proceedings of an international scientific conference. Danubius University, Sládkovicove, 17-27.

Golovko, L., Kutsevych, M., Serediuk, V., Bogdan, O. (2020). Implementation of EU Environmental Policy in Ukraine: Directions and Perspectives. European Journal of Sustainable Development, Volume 9, № 4, 191-198.

How artificial intelligence can help education. (2020). Retrieved from: https://osvitoria.media/experience/yak-shtuchnyj-intelekt-mozhe-dopomogty-osviti/

IEEE. Ethics in Action. (2016). Retrieved from: https://ethicsinaction.ieee.org/

Join the discussion of the Concept of Artificial Intelligence Development in Ukraine. (2020). https://thedigital.gov.ua/news/doluchaytes-do-obgovorennya-kontseptsii-rozvitku-sferishtuchnogo-intelektu-v-ukraini

Judgment of the Court (Fourth Chamber) of 16 July 2009. Infopaq International A/S v Danske Dagblades Forening. Case C-5/08. European Court Reports 2009 I-06569

Kachur, V., Protosavitska, L., Zasukha, L., Golovko L. (2020). The Role of Legal Culture in Maintaining Social Stability and Countering Separatist Movements: Case of Ukraine. European Journal of sustainable development, Volume 9, № 1, 294-299.

Kahneman, Daniel. Thinking, Fast and Slow. (2011). New York: Farrar, Straus and Girous.

Karácsony Gergely G. (2019). Managing personal data in a digital environment - did GDPR's concept of informed consent really give us control? Computer law, AI, data protection and the biggest technological trends. Proceedings of an international scientific conference. Danubius University, Sládkovicove, 39-49.

Karchevsky, M.V. (2017). The main problems of legal regulation of socialization of artificial intelligence. Bulletin of Luhansk State University of Internal Affairs named after E. A. Didorenko, 2, 99-108.

Khrisanova, E. (2019). Emotional AI. Retrieved from: https://rb.ru/longread/emotion-ai/

Kidalov, S., Vitiv, V., Golovko, L., Ladychenko, V. (2020). Legal Regulation of Waste Management in Ukraine on the Way to European Inregration. European Journal of sustainable development, Volume 9, № 2, 422430.

Klimek, L. (2019). Criminal issues of torrents and copyright infringement Computer law, AI, data protection and the biggest technological trends. Proceedings of an international scientific conference. Danubius University, Sládkovicove, 67-72.

Kravchuk, S., Borovikova, V. (2019). Lawyer of the future - in cooperation with artificial intelligence. Retrieved from: https://www.ukrlogos.in.ua 
Kryvecky, O. (2017). On the issue of artificial intelligence. Retrieved from: http://nbuviap.gov.ua/index.php?option $=$ com content\&view $=$ article\&id $=3728$ :do-problemipravovogo-regulyuvannya-shtuchnogo-intelektu\&catid $=8 \&$ Itemid $=350$

Kulynych, V. (2020). How Artificial Intelligence Helps Fight Coronavirus. Retrieved from: https://nv.ua/techno/technoblogs/epidemiya-koronavirusa-kak-iskusstvennyy-intellektpomogaet-diagnostirovat-bolezn-50080013.html

Kutsevych, M., Yara, O., Golovko, L., Terpeliuk, V. (2020). Sustainable Approaches to Waste Management: Regulatory and Financial Instruments. European Journal of sustainable development, Volume 9, № 2, 163 171.

Ladychenko, V., Golovko L. (2018). The Right to Access to Environmental Information in Ukraine and the EU. European Journal of sustainable development, Volume 7, № 3, 455-459.

Ladychenko, V., Yara, O., Uliutina, O., Golovko, L. (2019). Environmental Liability in Ukraine and the EU. European Journal of Sustainable Development, Volume 8, № 2, 261-267.

Mesarčík, M. (2018). Selected issues of predictive policing in the light of new data protection rules in the EU. Get ready for 2018's changes to EU data protections laws 2018, p. 39-48.

Pierce D., Hathaway A. (2018) The Promise (and Pitfalls) of AI for Education, Artificial intelligence, 8 (29). Retrieved from: https://thejournal.com/Articles/2018/08/29/The-Promise-of-AI-for-Education.aspx?Page=2

Price, H., Tallinn, J. (2012). Artificial Intelligence - Can We Keep It in a Box? Retrieved from: https://world.edu/artificial-intelligence-can-we-keep-it-in-the-box/

Rowe, J.P., Lester, J.C. (2020). Artificial Intelligence for Personalized Preventive Adolescent Healthcare. Journal of Adolescent Health, 67(2), 52-58.

Schwantner, M. Sesytsky, E. (2018). Legal protection of Works Generated by Artificial IntelligenceSystems: the Experience of the EU, Great Britain and the United States, Journal of Kyiv University of Law, 4, 2010-219.

The Ministry of Justice has started using artificial intelligence to work with criminals. (2020). Retrieved from: https://zaxid.net/minyust pochav vikoristovuvati shtuchniy intelekt dlya roboti zi zlochintsyami n $\underline{1507619}$

Traffic in Ukraine will be controlled by artificial intelligence. (2020). Retrieved from: https://autokyiv.info/2020/10/16/trafikom-v-kyyevi-upravlyatyme-shtuchnyj-intelekt/

Vlasyuk, V. (2020). Artificial Intelligence Needs Lawyers. Retrieved from: https://nv.ua/opinion/iskusstvennyyintellekt-i-pravo-kak-ogranichit-ushcherb-ot-iskusstvennogo-intellekta-novosti-ukrainy-50113314.html

Vlasyuk, V. (2020). Artificial Intelligence: Course on Legal Settlement. Retrieved from: https://www.epravda.com.ua/rus/columns/2020/08/11/663902/

Young, E.A. Popular Algorithm is no better at predicting crimes than random people. (2018). Retrieved from: https://www.theatlantic.com/technology/archive/2018/01/equivant-compas-algorithm/550646/

Zaiets, S. (2020). Can a robot judge a person? Retrieved from: https://www.pravda.com.ua/rus/columns/2020/05/28/7253558/ 